\title{
An evaluation of an oral health training programme for carers of the elderly in residential homes
}

\author{
D. Simons, ${ }^{1}$ P. Baker, ${ }^{2}$ B. Jones, ${ }^{3}$ E. A. M. Kidd, ${ }^{4}$ and D. Beighton, ${ }^{5}$
}

\begin{abstract}
Objective The objectives of this study were: to evaluate carers' knowledge of oral health; to provide a high quality, consistent, oral health training programme for carers in residential homes; to evaluate the quality of this programme by examining both carers' changes in knowledge and any changes in carers' behaviour as reported by residents and to assess any changes in the oral health of the elderly residents after one year.

Design A cross-sectional, multi-centre study using a carer training programme, evaluated by both a questionnaire conducted with carers and residents and oral examination of residents.
\end{abstract}

Setting In August 1996, 20 (20\%) of the residential/nursing homes, in West Hertfordshire were chosen at random and all managers contacted and offered an oral examination for all their residents. Ten $(10 \%)$ of the homes were also offered an oral health training programme for their carers. Eighteen homes accepted the oral examination for all consenting residents and 7 of the 10 homes offered accepted the carer training.

Subjects Thirty-nine carers from 7 of the residential homes attended an oral health training course and 213 elderly residents in the 18 homes were examined both at baseline and after 12 months. Results Carers' baseline knowledge about oral health was poor; the oral health training programme was enjoyed and their knowledge gain after one week was high. However, the elderly residents perceived no change in the oral care given by carers either after one week or after one year and there was no measurable improvement in the oral health of residents after carer training, except for an increase in filled coronal surfaces. Few of the carers originally trained were still working in the same residential homes after one year.

Conclusion Although the carer training programme was well received, no changes in oral health practice resulted. Barriers to practice of oral care by carers remained and training, even when including practical skills, evaluation by peers and a high knowledge gain, failed to reduce these barriers.

Cor the first time since records have been kept, half the British Fopulation aged 65 years and older is dentate ${ }^{1}$ and this will have major implications for prevention, promotion and treatment dental services for years to come. High levels of oral disease have

\footnotetext{
${ }^{1}$ Senior Dental Officer, ${ }^{2}$ Senior Dental Officer, ${ }^{3}$ Senior Dental Officer, West Hert Community Dental Services, Dental Department, Principal Health Centre, Civic Close, St Albans, Herts AL1 3LA; ${ }^{4}$ Professor of Cariology, ${ }^{5}$ Professor of Oral Microbiology, Guy's, King's and St Thomas' Schools of Medicine and Dentistry and Biomedical Sciences, Guy's Campus, Guy's Hospital, London SE1 9RT Correspondence to D. Simons

REFEREED PAPER

Received 03.09.99; accepted 11.11.99

(C) British Dental Journal 2000; 188: 206-210
}

already been shown to exist in this age group. ${ }^{1-3}$ Comparisons of the oral health of the institutionalised elderly with those living at home have shown considerably higher levels of dental disease in those living in institutions. ${ }^{1-4}$ There are many barriers to appropriate oral healthcare among the elderly occupants of residential homes. These include cost, the residents' restricted mobility, low levels of perceived need by residents and staff, number of teeth and the carers' lack of dental knowledge. ${ }^{5}$ Elderly occupants of residential homes are often dependent on their carers to perform all their daily care and thus carers play a pivotal role in dental disease prevention. This may place considerable burdens on staff and it has been reported that the carers do not understand the importance of dental health or how to achieve it ${ }^{6}$ and that residents rarely receive more than emergency treatment for dental pain and discomfort. ${ }^{7}$

Solutions to these problems have included oral health education with elderly residents ${ }^{8}$ and training of carers ${ }^{6,9}$ but unfortunately these programmes have not always been successful. ${ }^{8-10}$ De Baat et al. ${ }^{11}$ in their review of the effectiveness of oral hygiene programmes for elderly people concluded that only well and not confused elderly can effectively participate in educational programmes and less well and confused elderly need regular professional support. The success of a procedure depends on the co-operation of care staff and requires in-service training and frequent monitoring. Several studies have shown a lack of knowledge about oral health amongst the carers of elderly people. Only $20 \%$ of directors of old people's homes in Finland considered dental care of elderly people more important than hairdressing. ${ }^{12}$ A recent assessment of nurse training establishments' commitment to the teaching of oral care revealed that it was often neglected and that recommended books were also inadequate. ${ }^{13}$ The importance of a basic oral health assessment and of oral care by nursing staff has been reported by several authors. ${ }^{14-15}$ The oral health assessment could be incorporated into routine assessment by care staff and from it continuing care arrangements organised. ${ }^{16}$

The aim of this study was to evaluate carer training in oral health with both objective and subjective criteria. This involved the following objectives:

- Investigation of carers' knowledge of oral health prior to the training.

- Oral examination/interviewing a sample of the elderly residents that the carers assisted with general/oral care.

- Provision of a high quality, consistent, oral health training programme.

- Evaluation of the quality of this programme by the carers.

- Examination of carers' changes in knowledge.

- Examination of any changes in behaviour of carers as reported by residents one week after the training.

- Assessment of changes in the oral health of the elderly residents one year after training. 


\section{Method and materials}

In August 1996, 20 of the 110 residential/nursing homes, in West Hertfordshire were chosen at random and all managers contacted and offered an oral examination for all their residents. Ten of the homes, were also offered an oral health training programme for their carers. Eighteen homes accepted the oral examination for all consenting residents and 7 of the 10 homes offered, accepted the carer training. This resulted in 7 homes receiving carer training and oral examination for residents and 11 receiving oral examination for the residents only. Appropriate dental management was provided for all residents who required oral care by either the resident's own general dental practitioner or the community dental service. Ethical approval was obtained from West Hertfordshire ethics committee.

Two hundred and forty-six elderly residents from the 18 homes were able and willing to consent to an oral examination and to respond to a structured interview. Details comprised the participants' age, gender, length of time in the home, funding arrangements and the type of dentures worn. A participant was recorded as wearing a denture if the denture was worn for more than 6 hours daily. All examinations took place in the morning, in an area of the home that afforded the resident privacy. A portable Daray light provided illumination. The examinations were carried out by a single examiner (DS) who was calibrated against another experienced examiner at the beginning, half-way through and at the end of the examinations. Intra-examination calibration was determined by re-examining $10 \%$ of the participants.

\section{Clinical examination}

Denture hygiene status was recorded by running a disposable $10 \mu \mathrm{l}$ bacteriological loop along the fitting and non-fitting denture surfaces and measuring the amount of plaque and debris collected:

$0=$ no plaque or debris

$1=$ presence of plaque/debris

$2=$ loop is half full of plaque/debris

$3=$ loop is full of plaque/debris

The Plaque Index ${ }^{17}$ and Gingival Index ${ }^{18}$ were recorded for buccal and palatal surfaces of all standing teeth. Teeth were subsequently cleaned with both a toothbrush and periodontal probe and isolated with cotton wool rolls. The examination was primarily visual with blunted and periodontal probes used solely for the removal of plaque and debris and for the detection of texture of certain lesions. The clinical status of each coronal tooth surface was scored according to the following criteria:

$$
\begin{aligned}
/= & \text { missing } \\
0= & \text { sound } \\
1= & \text { active caries (lesions of hard texture were not } \\
& \quad \text { designated as active) } \\
2= & \text { restored } \\
3= & \text { crown }
\end{aligned}
$$

The length of exposed root from cemento-enamel junction to the gingival margin and condition of each root surface was recorded ${ }^{19}$ as above. Root caries was defined as 'an area of exposed root at or below the cemento-enamel junction, where the texture of the lesion dictated operative treatment', eg soft or leathery and within $1 \mathrm{~mm}$ of the gingival margin. ${ }^{19}$ A root caries index (RCI) was calculated for each subject as defined by Katz (1980):

$$
\frac{(\mathrm{R}-\mathrm{D})+(\mathrm{R}-\mathrm{F})}{(\mathrm{R}-\mathrm{D})+(\mathrm{R}-\mathrm{F})+(\mathrm{R}-\mathrm{N})} \times 100=\mathrm{RCI}
$$

Where $(\mathrm{R}-\mathrm{D})=$ recession present + surface decayed, $(\mathrm{R}-\mathrm{F})=$ recession present + surface filled, $(\mathrm{R}-\mathrm{N})=$ recession present + surface normal or sound. Teeth that had no coronal surfaces remaining were recorded as retained roots and their root surface status was recorded separately. ${ }^{20}$

The questionnaire, in the form of a structured interview, was conducted with all those residents who were able to respond. There were 12 questions covering aspects of oral health and past dental care. Managers and deputy managers of the residential homes provided information on the dental care and attendance patterns of their residents.

\section{Oral health training course and carer's questionnaire}

The oral health training had been previously piloted with other carers and adapted as a result of the evaluation and had received NVQ accreditation. The three trainers were therapists and hygienists, members of the same dental team and had all had teaching qualifications in addition to their dental qualifications. All training sessions followed the same programme, the carer group sizes were between 4 and $8($ mean $=5.6)$. The session was conducted at the residential home and lasted for 90 minutes. It included an oral hygiene demonstration with disclosing and visualisation of plaque and various toothbrushing and denture cleaning techniques. There was practical involvement of the carers in cleaning each others' teeth, a video, information on diet and discussion time. The training incorporated recommendations made in other studies $9,21,22$ and the introduction of a basic oral health assessment and individual oral care plans for all residents to be included with their general healthcare plans. ${ }^{14-16}$ At the end of the session all participants received a training manual, a box of suitable samples and oral health aids, information leaflets and lists of places to obtain similar products.

The carers completed a baseline questionnaire prior to the session, a questionnaire subjectively evaluating the quality of the training at the end of the session and a follow-up questionnaire after 1 week evaluating knowledge changes. The multiple choice questionnaire was developed from that used to assess the 'Natural Nashers programme' and another evaluation study of carer training. ${ }^{22-23}$ At the end of this first week, the 87 residents who were previously examined in the seven homes in which the carers had been trained, completed a further questionnaire investigating if they perceived any changes in carer practices. Both the collection of the carers' questionnaires and the residents' follow-up interviews were conducted by dental nurses who were blind as to whether the questionnaires were baseline or post-training to avoid influencing any results obtained. After the completion of the follow-up questionnaire all carers' received a certificate which was NVQ recognised.

\section{Twelve month follow-up}

Twelve months after the carer training a check was made of how many of the original carers that attended the oral health training were still in post. Two hundred and thirteen of the original 246 residents were available to be re-examined. Only information obtained from those residents, who were present both at baseline and at the follow-up 12-month review is included in the study analysis. After the data was collected re-training or initial training was offered to all carers in the residential homes.

\section{Data analysis}

Categorical data were compared using $\chi^{2}$ test. Relationships between numerical data were determined using appropriate parametric or non-parametric tests. All data were analysed using the Statistical Package for the Social Sciences (SPSS) edition 8.0.

\section{Results}

The 213 residents examined both at baseline and at the end of 12 months comprised, 87 people living in the 7 homes that received carer training and 126 people from the 11 homes without. The residents 
personal details are presented in Table 1. There were no significant differences between the two groups of residents.

\section{Clinical examination}

The residents' oral health status is presented in Table 2, again there were no significant differences between the two groups.

\section{Oral health training course}

Thirty-nine carers in 7 homes participated in the carer training course. All carers were female with a mean age $34.9 \pm 16.4$ years. Thirty $(76.9 \%)$ of the carers had no formal training but had trained 'on the job', 6 (15.4\%) had NVQ training and 3 (7.7\%) were registered nurses. Carers had worked in residential homes for a range of $1-420$ months and put to bed/woke up between $0-8$ residents a day. There was no significance difference between the carers in the different homes. The carers baseline knowledge of oral disease was very poor (Table 3 ). However, all carers reported that it was important to clean residents teeth for $2.5 \pm 2.2$ mins daily, although in most responses the toothbrushing method and positioning of the resident was incorrect. Only $8(20.5 \%)$ of the carers had ever been given information on oral healthcare and $96 \%$ of the carers reported that residents complained of a dry or sore mouth, or problems with eating or tasting.

Subjective evaluation of the training showed that the sessions were well received and $38(97.4 \%)$ of the carers thought that the training was relevant to their job. One hundred per cent thought it met the stated objectives and found the session enjoyable. Thirtyseven $(94.8 \%)$ felt that all relevant aspects of oral care for their residents were included. Thirty-six $(92.3 \%)$ found the level of information appropriate and $100 \%$ found the practical oral hygiene section valuable with $12 \%$ requesting more information in another session. The results of the questionnaire, evaluating knowledge gain, 1 week after the training session, are compared with the baseline knowledge questionnaire results in Table 3. Although the carers' knowledge gain appeared significant, the 87 residents in their questionnaire responses, carried out 1 week after their carers' training, reported no changes in carers' behaviour. The residents questionnaire responses are given in Table 4.

\section{Twelve month follow-up}

After 12 months the 213 residents were re-examined and their oral health status can be seen in Table 2. There was a significant increase in coronal filled surfaces in both groups $(P<0.05)$ but no changes in any other indices. There were no significant differences between the elderly residents in the residential homes that had received carer training and those homes that had not. Only 14 of the 213 residents had oral healthcare plans completed after 1 year. Ten residents were in one home that had received carer training and 4 in another that
Table 1 Residents' personal details

\begin{tabular}{lcc}
\hline Personal Details & $\begin{array}{c}\text { Residential homes } \\
\text { with carer training } \\
(n=87)\end{array}$ & $\begin{array}{c}\text { Residential homes } \\
\text { without carer training } \\
(n=126)\end{array}$ \\
\hline $\begin{array}{l}\text { No. of women } \\
\text { No. of men }\end{array}$ & $61(70 \%)$ & $91(72 \%)$ \\
$\begin{array}{l}\text { Mean age of residents } \\
\text { Mean no. of months spent }\end{array}$ & $26(30 \%)$ & $35(28 \%)$ \\
living in home & $21.9 \pm 6.8$ & $83.8 \pm 6.6$ \\
$\begin{array}{l}\text { No. of residents funded } \\
\text { by social services }\end{array}$ & $69(79 \%)$ & $19.9 \pm 21.1$ \\
\hline
\end{tabular}

had not. In this second home the plans had been completed by the oral health educator from the community dental service, although they were supposed to be completed by residential care staff. Analysis of the residents' questionnaire responses after 12 months also showed no significant differences between those homes that had carer training and those that did not (Table 5). Only 21 (53.8\%) of the original carers who were trained still worked in the 7 homes.

\section{Discussion}

The aim of this study was to evaluate carer training in oral health with both objective and subjective criteria. It proposed to do this by examining carers' change in knowledge and any changes in behaviour of carers as reported by residents and to assess the training in terms of oral health gain of these residents after 12 months. Using a varied team of people in the organisation of the trial and completion of questionnaire/interviews was intended to eliminate bias in responses from residents and carers.

\section{Clinical examination}

The elderly occupants of the residential homes examined in this study were found to experience poor oral health, high plaque levels (range $=2.4 \pm 0.8-2.5 \pm 0.6)$, coronal decay $($ range $=3.9 \pm 8.4-4.0$ \pm 7.4 ) and a root caries index comparable with the high levels of disease found in other similar populations. ${ }^{1,3-4}$ The baseline screening programme resulted in dental management of all residents requiring and willing to undergo dental care. This included specific oral hygiene care plans for residents, provision of preventive dental care, including fluoride applications, provision of restorations, extractions, provision of dentures and any other care required. This was offered to all people in the homes screened and may explain the significant increase in coronally filled surfaces, although no other indices changed. Table 2 shows clearly that the oral care instituted by the dental team or the carers failed to prevent further caries, although perhaps the deterioration would have been more marked without the preventive advice, training and management.

Table 2 Residents oral health status at baseline and after 12 months

\begin{tabular}{|c|c|c|c|c|}
\hline \multirow[b]{2}{*}{$\begin{array}{l}\text { Oral Health Status of } \\
\text { Residents }\end{array}$} & \multicolumn{2}{|c|}{ Baseline } & \multicolumn{2}{|c|}{12 months later } \\
\hline & $\begin{array}{l}\text { Homes with } \\
\text { carer training } \\
(\mathrm{n}=87)\end{array}$ & $\begin{array}{l}\text { Homes without } \\
\text { carer training } \\
\quad(n=126)\end{array}$ & $\begin{array}{l}\text { Homes with } \\
\text { carer training } \\
(\mathrm{n}=87)\end{array}$ & $\begin{array}{l}\text { Homes without } \\
\text { carer training } \\
(n=126)\end{array}$ \\
\hline No. of edentate residents & $48(55 \%)$ & $72(57 \%)$ & $51(59 \%)$ & $72(57 \%)$ \\
\hline No. of dentate residents & $39(45 \%)$ & $54(43 \%)$ & $36(41 \%)$ & $54(43 \%)$ \\
\hline No. of residents with no teeth/dentures & $9(10 \%)$ & $10(8 \%)$ & $12(14 \%)$ & $10(8 \%)$ \\
\hline Mean no. of teeth & $5.4 \pm 8.2$ & $5.6 \pm 8.1$ & $5.2 \pm 9.1$ & $5.3 \pm 7.6$ \\
\hline Mean no. of coronal decayed surfaces & $4.0 \pm 7.4$ & $3.9 \pm 8.4$ & $3.8 \pm 9.4$ & $4.2 \pm 9.6$ \\
\hline Mean no. of coronal filled surfaces & $8.5 \pm 11.5$ & $9.8 \pm 13.8$ & $10.9 \pm 11.9 *$ & $12.3 \pm 11.2^{*}$ \\
\hline Plaque index & $2.5 \pm 0.6$ & $2.4 \pm 0.8$ & $2.6 \pm 0.8$ & $2.4 \pm 0.6$ \\
\hline Gingival index & $2.2 \pm 0.9$ & $2.1 \pm 1.0$ & $2.4 \pm 0.9$ & $2.2 \pm 1.0$ \\
\hline Root caries index & $48.1 \%$ & $47.5 \%$ & $50.2 \%$ & $49.7 \%$ \\
\hline No. of retained roots & $0.6 \pm 1.6$ & $0.5 \pm 1.5$ & $0.4 \pm 1.0$ & $0.6 \pm 1.6$ \\
\hline Denture debris level & $2.1 \pm 1.1$ & $1.9 \pm 1.8$ & $2.0 \pm 1.3$ & $2.1 \pm 1.7$ \\
\hline
\end{tabular}

${ }^{*} P<0.05$ when compared with findings 12 months previously 
Table 3 Comparison of carer's baseline and post training knowledge $(n=39)$

\begin{tabular}{|c|c|c|}
\hline & $\begin{array}{c}\text { Response at baseline } \\
\text { no. }(\%)\end{array}$ & $\begin{array}{c}\text { Response post-training } \\
\text { no. } \quad(\%)\end{array}$ \\
\hline $\begin{array}{l}\text { Correctly identified the causes of tooth decay } \\
\text { Correctly identified the causes of gum disease } \\
\text { Knew the best place to stand when cleaning a resident's teeth } \\
\text { Knew the recommended amount of toothpaste } \\
\text { Understood what plaque was } \\
\text { Understood the significance of bleeding gums } \\
\text { Identified the colour of healthy gums }\end{array}$ & $\begin{array}{lr}4 & (10 \%) \\
6 & (15 \%) \\
2 & (5 \%) \\
1 & (3 \%) \\
2 & (5 \%) \\
0 & (0 \%) \\
9 & (23 \%)\end{array}$ & $\begin{array}{lr}22 & (56 \%) \\
31 & (80 \%) \\
39 & (100 \%) \\
19 & (49 \%) \\
24 & (62 \%) \\
17 & (44 \%) \\
32 & (82 \%)\end{array}$ \\
\hline
\end{tabular}

Table 4 Resident questionnaire responses

\begin{tabular}{lcc}
\hline Questions & $\begin{array}{c}\text { Responses of the } \\
\text { residents at baseline } \\
(n=213) \\
\text { no. }(\%)\end{array}$ & $\begin{array}{c}\text { Responses of the residents } \\
\text { after carer training } \\
(n=87) \\
\text { no. }(\%)\end{array}$ \\
\hline $\begin{array}{l}\text { Experienced problems } \\
\text { looking after mouth }\end{array}$ & $64(30 \%)$ & $25(29 \%)$ \\
$\begin{array}{l}\text { Received assistance } \\
\text { cleaning teeth/dentures }\end{array}$ & $18(9 \%)$ & $7(8 \%)$ \\
$\begin{array}{l}\text { Would like assistance } \\
\text { cleaning teeth/dentures }\end{array}$ & $70(32 \%)$ & $25(29 \%)$ \\
$\begin{array}{l}\text { Teeth/dentures cleaned twice daily } \\
\text { Teeth/dentures cleaned once daily }\end{array}$ & $86(37 \%)$ & $30(35 \%)$ \\
\hline
\end{tabular}

\section{Table 5 Resident's responses after 12 months according to carer} training status

Residents' responses

Homes without carer Homes with carer

$\begin{array}{ll}\text { training. } & \text { training } \\ (n=126) & (n=87)\end{array}$

no. $(\%)$

no. $(\%)$

Experienced problems

$39(31 \%)$

$27(31 \%)$

looking after mouth

$14(11 \%)$

$8(9 \%)$

teeth/dentures

Would like assistance cleaning

$39(31 \%)$

$26(30 \%)$

teeth/dentures

Teeth/dentures cleaned twice daily

Teeth/dentures cleaned once daily

$49(39 \%)$

$44(35 \%)$

$33(26 \%)$

$31(36 \%)$

$41(47 \%)$

$15(17 \%)$

than once daily

Consideration needs to be given to the very low numbers of community dental service staff and the time they have available, in comparison to the large number of the population needing care. Both time and resources are extremely limited for dental staff and the carers and this needs to be addressed if effective management of oral health is to be instituted. In 1999 Watt \& Sheiham ${ }^{24}$ stated that there was no evidence to support that increasing provision of dental services decreases inequity in oral health and that cost/benefit ratio of this approach is poor. They suggested that funds would be better directed at public preventive approaches. However, they did state that the one group who would benefit from more care were older people and that improvements in oral quality of life measures were significant and food choices increased as the elderly chewed better. ${ }^{24}$

\section{Oral health training course}

The empirical method of addressing poor standards of residents' oral health has been recommendations for training and improving knowledge of the carers. ${ }^{25}$ Past studies involving carer training have shown knowledge gain. ${ }^{25}$ However, while oral health education has been shown to be effective at increasing knowledge levels, no evidence exists to show that changes in knowledge are causally related to changes in behaviour. Reported behaviour and behavioural intention can be altered, but there is no evidence that oral health promotion is able to effect dietary practices to an extent whereby caries levels are reduced. ${ }^{26}$ Davies \& Whittle's study in 1990 reported that those carers who attended a dental hygiene session knew more about dental health than those who had not, ${ }^{22}$ but no research has shown this gain in knowledge to be effective at changing carers' behaviour or decreasing the levels of oral disease in the elderly residents. A recent paper by Paulsson et al. 1998 showed a change of attitudes among nursing personnel towards provision of oral care, after the oral health training was specifically geared towards the educational level of the staff. However, health gain to the care receivers was not measured. ${ }^{27}$ A published abstract showed reductions in plaque, denture stomatitis and improved gingival health of residents, following an oral health education programme for carers in nursing homes. Although the author concluded that resident's oral health was still short of ideal. ${ }^{28}$

In this current study, carers' knowledge about oral health was found to be very poor and the carers' had received little formal training with the majority being trained 'on the job'. The paucity of specific dental knowledge at baseline has also been noted in other studies. ${ }^{26}$ The oral health programmes used in this study were previously evaluated and adapted by other groups of carers of elderly people and included recommendations from other studies and guidelines of specialist societies. ${ }^{9,22,29-30}$ Prior to the study it was planned to provide between two to three sessions of training, spaced over a few weeks, so that knowledge and behaviour could be reinforced, questions answered and support for problems given. However, the managers refused to allow staff to be absent from their duties for this amount of time and staff felt that they could not afford to attend sessions outside working hours, so the training was organised as a single session. This appears to show both the difficulty of removing carers from their daily workload and the low priority given to oral care, both among staff and managers, in residential homes.

The oral health training programme was enjoyed by the carers and their knowledge gain after 1 week was high but the results still showed that it failed to produce measurable changes in oral health practice. The elderly residents perceived no change in the oral care given by carers 1 week after the carer training. This could be because of residents' lack of perception, or because a week was not long enough for the carers to organise the suggested oral hygiene aids, gloves, or time required to provide oral care. Equally it may be because no change was going to be initiated. Although it is unrealistic to expect a 90 minute programme to lead to behaviour change among these carers, who have a workload that allows little flexibility, it remains disheartening that no noticeable changes were produced. The community dental team remained available for support post-training and attended the homes on a regular basis to provide dental care for specific residents. This allowed for even further input and information, but despite this the results still showed no change in health related behaviours of carers.

\section{2-month follow-up}

After 1 year there were no measurable improvements in the oral health of residents or responses from the residents indicating oralcare had increased. Care plans, despite being provided free of 
charge, introduced during the training and then subsequently at treatment visits, failed to be completed even though they were integrated into all the residents general medical care plan folders.

Although all of the carers' reported that it was important to clean resident's teeth and $78.2 \%$ felt it should be conducted twice daily, the residents responses indicated that the frequency of twice-daily tooth and denture cleaning was much lower at $27.5 \%$. Research has shown that even carers with good personal oral hygiene habits find it more disagreeable to clean other peoples mouths than their other nursing activities. ${ }^{31}$ Registered nurses have a more positive attitudes toward oral care assistance than other nursing groups, but these nurses are seldom found to be involved in the daily practice of oral hygiene care. ${ }^{31}$

We should not lose sight of the reality of the situation in nursing and residential homes where qualified nurses are in short supply and the majority of services are undertaken by carers who have little or no qualifications, are poorly paid and where staff turnover is high. ${ }^{32}$ Significantly few of the carers originally trained in this study, were still working in the same residential homes after 1 year. This high staff turnover could be a major inhibiting factor in the effectiveness of all training programmes. ${ }^{33}$

Attempts to improve oral hygiene and reduce sugar consumption require intensive effort and this may explain why attempts are often unsuccessful and why when recommendations to improve knowledge are made, this rarely affects behaviour. Carers' often have little control over the sugar consumption of residents, it is often the management who plan the residents' meals and snacks. The authors tried to address this issue by involving the managers in the carer training and its evaluation. However, none of the staff exert any control over the gifts friends and relatives provide and possibly information for these individuals may be required.

A gap between knowledge and practice in nursing personnel attitudes towards oral health has been reported. The carers' deep rooted attitudinal problems cannot be resolved by information or leaflets alone, but by bringing about fundamental changes in attitudes towards the issue. Such a change can be achieved only by developing comprehensive oral health care programmes aimed at changing attitudes as well as providing carers with necessary skills and resources to take the appropriate action. ${ }^{29,34}$ This programme followed the recommendations of earlier research; it included prior evaluation of the training, inclusion of a large practical component, involvement of the managers and accreditation of training for NVQ. However, despite these efforts, no changes in carer behaviour or beneficial effect of increased care could be shown. The possible reasons could be a lack of time, lack of incentive, uncooperative residents, the unpleasantness of the job and that one training session, even followed by dental support, will not make a difference to behaviour. The solution to this problem remains to be addressed. It is poignant to note that in the past, most of the elderly in institutions were edentulous, so oral care healthcare services were not urgently needed, as the staff could always remove the dentures and place the person with problems on a soft diet. However, all recent evidence shows that this situation is changing and the increase in residents with natural teeth increases the need for oral healthcare and services. ${ }^{35}$

The authors would like to thank all the managers, carers and residents for their assistance with this study. They would also like to thank the Shirley GlasstoneHughes Memorial Fund, West Hertfordshire Community Health NHS Trust, Ms G Lowey and Fertin A/S for their kind support.

1 Steele J G, Sheiham A, Marcenes W, Walls A W G. National diet and nutrition survey: people aged 65 years and over. Vol. 2: Report of the oral health survey. London: The Stationery Office,1998.

2. Simons D, Kidd E A M, Beighton D. Oral health of elderly occupants in residential homes. Lancet 1999; 353: 1761.

3. Jokstrad A, Ambjornsen E, Eide K E. Oral health in institutionalised elderly people in 1993 compared with 1980. Acta Odont Scand 1996; 54: 303-308.
4. Vigild M. Dental Caries and the need for treatment among institutionalised elderly. Community Dent Oral Epidemiol 1989; 17: 102105

5. Hoad-Reddick G. Summary. Br Dent J 1998; 184: 288.

6. Glassman P, Miller C, Woznick T, Jones C. A preventive dentistry training programme for caretakers of persons with disabilities residing in community residential facilities. Spec Care Dent 1994; 14: 137-143.

7. Merelie D L, Heyman B. Dental needs of the elderly in residential care in Newcastle-upon-Tyne and the role of formal carers. Community Dent Oral epidemiol 1992; 20: 106-111.

8. Schou L, Wright C, Clemson N, Douglas S, Clark C. Oral health programme for institutionalised elderly. Community Dent Oral Epidemiol 1989; 17: 2-6.

9. Fiske J, Lloyd H A. Dental needs of residents and carers in elderly peoples homes and carers attitudes to oral health. Eur J Prosthodont Rest Dent 1992; 1: 91-95.

10. Mann J, Wolnerman T, Lavie G, Carlin Y, Meir S, Garfunkel A. The effect of dental education and dental treatment on the dental status of a handicapped population: a longitudinal study. Special Care Dent 1986; 180 181.

11. De Baat C, Kalk W, Schuil G R E. The effectiveness of oral hygiene programmes for elderly people - a review. Gerodontology 1993; 10: 109-113.

12. Ekelund R. National survey of oral health care in Finnish private old people's homes. Community Dent Oral Epidemiol 1989; 17:158-161.

13. Longhurst $\mathrm{R} H$. A cross sectional study of the oral healthcare instruction given to nurses during their basic training. Br Dent J 1998; 184: 453-457.

14. Sampson P, Page C, Shepard G. Oral hygiene: the mouth trap. Nursing Times 1987; 83: 19.

15. Griffiths J, Boyle S. Oral assessment in color guide to holistic oral care: a practical approach. pp 87-98. Mosby Year Book Europe Ltd, 1993.

16. Hoad-Reddick G. Assessment of elderly people on entry to residentila homes and continuing care arrangements. J Dent 1992; 20: 199-201.

17. Loe H, Silness J. Periodontal disease in pregnancy I. Prevalence and severity. Acta Odontol Scand 1963; 21: 533-551.

18. Silness J., Le H. Periodontal disease in pregnancy. II. Correlation between oral hygiene and periodontal condition. Acta Odontologica Scand 1964; 22: 121-135.

19. Beighton D, Lynch E, Heath M. A microbiological study of primary root caries lesions with different treatment needs. J Dent Res 1993; 72: 623-629.

20. Katz R. Development of an Index for the prevelance of root caries. J Dent Res 1984; 63: 814-819.

21. Logan H, Ettinger R, McLeran H, Casko R. Common misconceptions about oral health in the older adult: nursing practices. Special Care Dent 1991; 11: 243-247.

22. Davies K W, Whittle J G. Dental health education: training of homecarers of mentally handicapped adults. Comm Dent Health 1990; 7: 193-197.

23. Craft M, Croucher R, Dickinson J. Preventive dental health in adolescents: short and long term pupil response to trials of an integrated curriculum package. Community Dent Oral Epidemiol 1981; 9: 199-206.

24. Watt $R$, Sheiham A. Inequalities in oral health: a review of the evidence and recommendations for action. Br Dent J 1999; 187: 6-12.

25. Rak O S, Warren K. An assessment of the level of dental and mouthcare knowledge amongst nurses working with elderly patients.Community Dental Health 1990; 7: 295-301.

26. Kay E, Locker D. Effectiveness of Oral Health Promotion-a Review. London: HEA, 1997.

27. Guidelines for standards of dental care for people with disabilities. British Society of Dentistry for the Handicapped, 1996.

28. Frenkel H. A health education intervention to improve the oral health of institutionalised elderly people: a randomised controlled trial. Abstract BSDH 1998 http;//www.bsdh.org.uk

29. Paulsson G, Fridlund B, Holmen A, Nederfors T. Evaluation of an oral health education programme for nursing personnel in special housing facilities for the elderly. Special Care Dent 1998; 18: 234-242.

30. Oral Health Working Group, U.S. Surgeon Generals Workshop: Health Promotion and Aging. Recommendations for Oral Health Promotion activities with older adults. Gerodontics 1988; 4: 207-208.

31. Wardh I, Andersson L, Sorensen S. Staff attitudes to oral health care. A comparative study of registered nurses, nursing assistants and home care aides. Gerodontology 1997; 14: 28-32.

32. Hamilton F. Summaries. Br Dent J 1998; 184: 23.

33. Glassman P, Miller C, Wozniak T, Jones C. A preventive dentistry training program for caretakers of persons with disabilities residing in community residential facilities. Special Care Dent 1994; 14: 137-143.

34. Schou L, Holm-Pedersen P, Lang N. Preventive dental care for elderly people. In Textbook of Gerodontology. pp302-318 Copenhagen: Munksgaard, 1997.

35. Ettinger R. Oral health programs for homebound elderly. In Textbook of Gerodontology. pp536-559 Copenhagen: Munksgaard, 1997. 